\title{
A Tool and Method for Extracting Plant-Root-Soil Cores on
}

Remote Sites

\section{GARY R. BROWN AND JOHN F. THILENIUS}

Highlight: A portable, man-operated tool for extracting intact cores of soil, roots, and above-ground plant parts on sites inaccessible to motor vehicles can be constructed for less than $\$ \mathbf{1 2 5 . 0 0}$. Two men can extract up to 125 cores in 4 hours.

For a study of above- and below-ground biomass production of alpine and subalpine ranges in Wyoming (Thilenius 1975) we needed a coring tool to obtain intact samples of above-ground plant parts, roots, and soil on sitcs which were not accessible to motor vehicles. The tool had to (1) be easily portable, (2) be man-operated, and (3) cut and remove cores rapidly.

\section{Design and Methodology}

The tool we built (Fig. 1) has a cutting head patterned after that of the common soil bulk-density sampler (Blake 1965), but has a much longer tube so long cores could be extracted in one piece. Two handles are welded to the tube to aid in pulling it from the ground.

The authors are, respectively, range research technician and range scientist, Rocky Mountain Forest and Range Experiment Station, Forest Service, U.S. Department of Agriculture. Research reported here was conducted at the Section's Research Work Unit at Laramie, in cooperation with the University of Wyoming. Station's central headquarters is maintained at Fort Collins, in cooperation with Colorado State University.

Manuscript received April 21, 1976
Our original idea was to drive the coring tool into the ground with a sledgehammer. However, this method damaged the upper part of the tube, even though it had been reinforced. More importantly, the cutting edge was chipped and bent from contact with rocks in the soil. Pounding was also slow, required considerable physical effort, and meant the extra weight of a heavy sledgehammer had to be carried.

During preliminary trials we discovered the tool could be twisted into the ground without pounding: One person kneels, grasps the handles of the corer, and holds it upright, while a second person stands on the tool, his feet on the handles immediately next to the tube. By placing his hands on the shoulders of the kneeling person, the standing person can maintain his balance and still have most of his weight on the tool (Fig. 2). The kneeling person then twists the tool back and forth around its axis so it drills into the ground. The combination of weight and twisting motion makes it relativcly easy to push the tool into the ground.

After the tool penetrates to the desired depth the person standing on the tool steps off and pulls the tool from the ground with a twisting motion. We obtained intact cores 20 inches $(50.8 \mathrm{~cm})$ long without difficulty. The large root mass and generally moist soil conditions of alpine sites prevented the soil core from falling apart or dropping out of the tool.

We first put the extracted cores in heavy plastic bags for transportation from the field. Normal movements while transporting the cores either by backpacking or on a packhorse caused soil material and above-ground plant parts to become mixed, with consequent damage to the plant parts and loss of soil material. Even when undamaged, the 


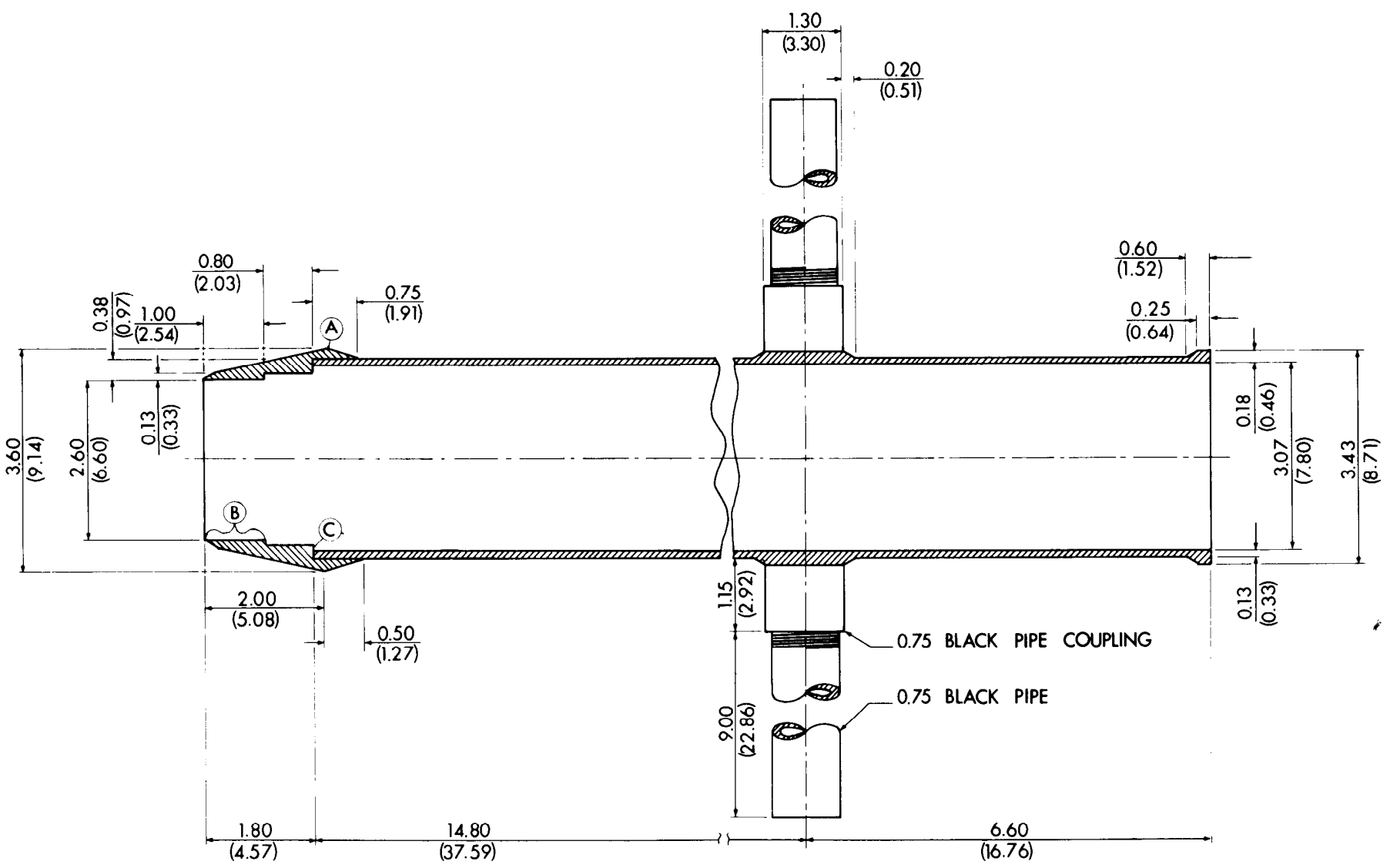

Fig. 1. Plan and dimensions of the coring tool. Metric dimensions in ().

plant parts were coated with soil, which made identification and weight determination difficult or impossible. We corrected this problem by using rigid plastic cylinders instead of bags (Fig. 3). The ends of the cylinders were sealed with removable plastic caps and carried with the above-ground plant parts uppermost. The cylinders can be placed in the corer either before or after the corer is twisted into the ground.

The extracted cores could be stored in the cylinders at $-5^{\circ} \mathrm{F}$ $\left(-22^{\circ} \mathrm{C}\right)$ for up to 3 months without damage to the above-ground plant parts. Absence of damage may be due to the cold-resistent nature of the high-elevation plant species we sampled.

\section{Construction and Materials}

The dimensions of the coring tool we developed are given in Figure 1. Actual measurements are not critical and may be altered to suit the requirements at hand. However, some design elements are critical. The first of these is the rounded bulge (A) on the cutting head. This

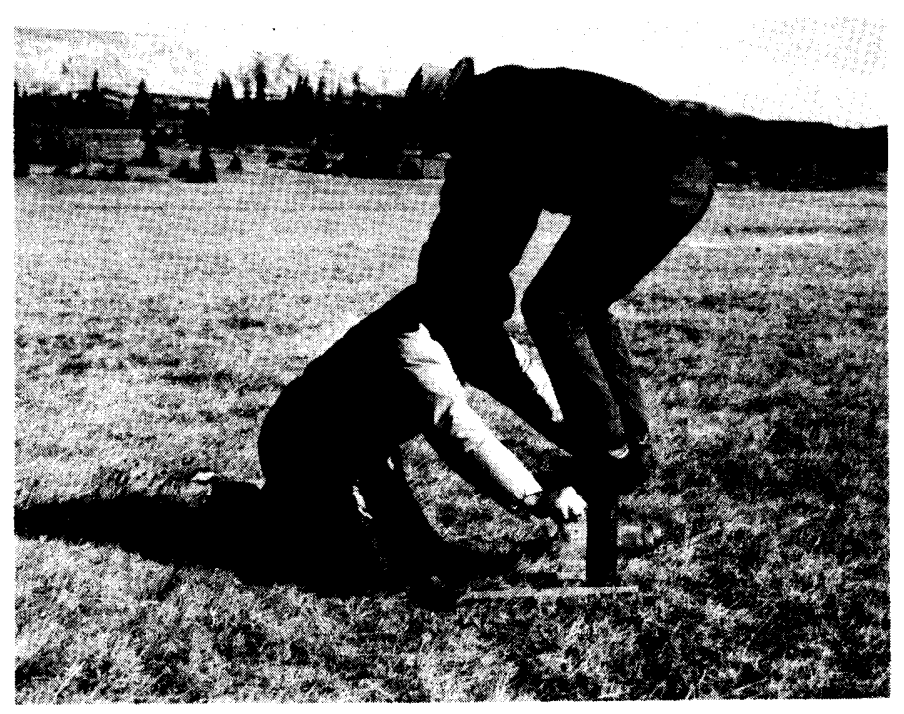

Fig. 2. Two persons are required for the coring operation.

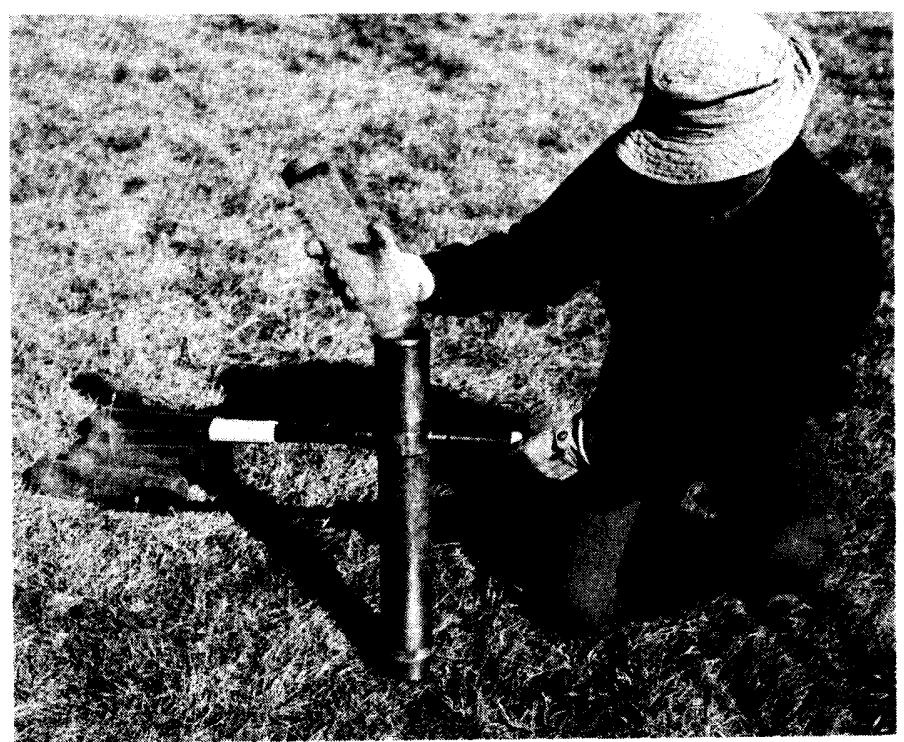

Fig. 3. Plastic cylinder being inserted into the coring tool. 
causes the hole made by the tool to be slightly larger than the outside diameter of the tube, and eliminates much of the friction between the outside of the tube and the surrounding soil as it moves into the ground.

A second critical element is the length of the surface just inside the cutting head (B). This should be made as short as possible (without loss of strength) to minimize contact, and consequently friction, between the core itself and the tool.

The inside diameter at $\mathbf{B}$ determines the diameter of the core. The diameter at $\mathbf{B}$ must be slightly less than the inside diameter of the plastic carrying cylinder so the core does not bind as it moves into the cylinder. The outside diameter of the carrying cylinder determines the inside diameter of the tube, which should be large enough so the cylinder slides easily into the tube. A retaining shoulder $(\mathbf{C})$ is machined on the inside of the cutting head to keep the plastic cylinder in the tube.

The tube of the coring tool is made from steel pipe machined on a lathe to the required dimensions. Reinforcing strips are left at the top and where the sockets for the handles are welded to the tube. Handles are 0.75 inch $(1.9 \mathrm{~cm})$ diameter galvanized iron water pipe; the sockets are pipe couplings. We fitted the handles with bicycle handlebar grips to prevent blisters.

The cutting head is machined separately from the tube and attached to it by silver soldering. This method of attachment allows removal (by heating) and replacement should the bit become badly damaged. We believe silver soldering is a sufficiently strong method of attachment. We extracted more than 5,000 cores over a 2 -year period without any loosening of the cutting head and believe silver soldering to be a stronger method of attachment than threading. The edge of the cutting head is sharpened and treated with tungsten carbide applied by means of an acetylene torch (Eutalloy Process). ${ }^{1}$ This hardens the cutting edge and enables it to cut through or push aside small rocks without damage or undue effort on the part of the operator.

\section{Comments}

We believe the tool and method affords a relatively simple and efficient way to obtain samples of above- and below-ground biomass in remote locations. We were able to extract 125 cores in about 4 hours of actual working time. While we believe we solved the problem of

'Product names are included for the convenience of the reader. Mention of a specific product by name or manufacturer does not constitute endorsement by the U.S. Department of Agriculture. Prices are those paid in 1973. extracting cores, transporting them from the field may still be a problem. An average load of 30 cores in their tubes weighs approximately $100 \mathrm{lb}(45.5 \mathrm{~kg})$. While this weight can be backpacked for short distances, a packhorse is recommended, especially at elevations exceeding $10,000 \mathrm{ft}(3,048 \mathrm{~m})$.

\section{Materials and Costs 2}

A list of materials and suppliers we used is given below.

\section{Item}

Cost

Coring tool tube: 3.0 inch $(7.6 \mathrm{~cm})$ I.D. steel pipe 0.1875

inch $(0.48 \mathrm{~cm})$ wall thickness; 22.0 inch $(55.9 \mathrm{~cm})$ long $\$ 4.46$

Coring tool handles: 0.75 inch $(1.9 \mathrm{~cm})$ I.D. iron water pipe,

9.0 inch $(22.9 \mathrm{~cm})$ long (2)

Handle sockets: 0.75 inch $(1.9 \mathrm{~cm})$ pipe couplings (2)

Rubber bicycle handlebar grips (2)

Coring tool cutting head: 3.5 inch $(8.9 \mathrm{~cm})$ O.D. carbon steel seamless tubing

Tungsten carbide hardening material (Grittalloy \#10011)

Machinist's wages: 7 hours@\$15.00

Plastic cylinders: 3.0 inch $(7.6 \mathrm{~cm})$ I.D. plastic tubing. $\$ 2.40 / \mathrm{ft}(30.5 \mathrm{~cm})$. Available in 6-ft $(193 \mathrm{~cm})$ lengths.

Plasticrafts Inc.

2800 N. Speer Blvd.

Denver, Colorado 80211

Plastic caps for cylinders: 3.0 inch $(7.6 \mathrm{~cm})$ I.D. $\$ 0.03$ each. Caplugs Division, Protective Closures Co.

2150 Elmwood Ave.

Buffalo, New York 14207

Approximate cost

\section{Literature Cited}

Blake, G. R. 1965. Bulk density. p. 375-377. In: C. A. Black (Ed.). Methods of soil analysis, Part 1. Amer. Soc. Agron. Madison, Wis., 1965. 770 p. Thilenius, John F. 1975. Plant production of three high elevation ecosystems, p. 60-76. In: D. H. Knight (Ed.). Final report: the Medicine Bow ecology project. Univ. of Wyoming, Rocky Mountain Forest and Range Exp. Sta., U.S. Forest Service and Wyoming Water Resources Research Institute. 379 p.
Statement of Ownership, Management and Circulation

(Act of August 12, 1970, Sec.3685, Title 39, United States Code)

1. Title of Publication: JOURNAL OF RANGE MANAGEMENT

2 Date of Filing: September 9, 1976

3 Frequency of issue: Bimonthly

4 Location of Office of Publication: 2120 S. Birch St., Denver, Colo. 80222

5 Location of General Business Office: Same

6 Names and Addresses of-

Publisher: Society for Range Management, 2120 S. Birch St., Denver, Colo. 80222

Editor: Elbert H. Reid, 624 S. Shields St., Fort Collins, Colo. 80521 Managing Editor: David A. Smith, 2120 S. Birch St., Denver, Colo. 80521

7. Owner: Society for Range Management, $2120 \mathrm{~S}$. Birch St., Denver, Colo. 80222. A nonprofit corporation; no capital stock authorized.

8. Known Bondholders, Mortgages, etc.: None

9. For Completion by Nonprofit Organization Authorized to Mail at Special Rates: The purpose, function, and nomprofit status of this organization and the exempt status for Federal income tax purposes have not changed during preceding 12 months.
10. Extent and Nature of Circulation:

A. Total copies printed

B. Paid circulation

1. Dealers, counter sales

2. Mail subscriptions

C. Total paid circulation

D. Free distribution

1. Samples, complimentary

2. To news agents, not sold

E. Total distribution

F. Office use, unaccounted

G. Total

$\begin{array}{rr}\begin{array}{c}\text { Avg. for } \\ 12 \text { months }\end{array} & \begin{array}{c}\text { Actual for } \\ \text { issue nearest } \\ \text { filing date }\end{array} \\ 5,894 & 5,861 \\ 0 & 0 \\ 5,484 & 5,633 \\ 5,484 & 5,633 \\ & \\ 25 & 28 \\ 0 & 0 \\ 5,509 & 5,661 \\ 385 & 200 \\ 5,894 & 5,861\end{array}$

I certify that the statements made by me above are correct and completeDavid A. Smith, Managing Editor. 